\title{
COMPARISON OF EFFECTS OF DIFFERENT NAIL TIP POSITIONS ON ANTERIOR KNEE PAIN AFTER INTRAMEDULLARY INTERLOCKING NAILING FOR TIBIAL SHAFT FRACTURES
}

\author{
Muhammad Hassan, Adnan Anwar*, Hassan Udin Hassan**, Muhammad Rehan Saleem***, Usman Arif ${ }^{* * * *}$ \\ Faisalabad Medical University Faisalabad Pakistan, ${ }^{*}$ Combined Military Hospital Abbottabad/National University of Medical Sciences (NUMS) Pakistan, ${ }^{* *}$ Khan \\ Research Laboratories Hospital Islamabad Pakistan, ${ }^{* * *}$ Combined Military Hospital Sialkot/National University of Medical Sciences (NUMS) Pakistan, \\ ${ }^{* * * * C}$ Combined Military Hospital/National University of Medical Sciences (NUMS) Rawalpindi Pakistan
}

\begin{abstract}
Objective: To determine the frequency of anterior knee pain after intramedullary interlocking nailing in tibial shaft fractures and to compare the intensity of anterior knee pain between positive and negative anterior cortex nail groups.

Study Design: Quasi-experimental study.

Place and Duration of Study: Department of Orthopaedic Surgery, Combined Military Hospital Rawalpindi, from Oct 2018 to Apr 2019.

Methodology: 100 cases of tibial shaft fracture were divided into two groups according to anterior cortex nail distance. Patients 18-40 years of age of both genders, closed fractures, Gustilo Andersen I open tibial diaphyseal fractures and nail tip more than $5 \mathrm{~mm}$ from tibial tuberosity were included. Patients with osteoarthritis, pathological fractures, renal disease, open fracture GA-II \& GA-III and knee instability were excluded from the study. Both groups with positive and negative anterior cortex nail distance were compared for pain using the chi-square test.

Results: Frequency of anterior knee pain after intramedullary interlocking nailing in tibial shaft fractures was found in $24 \%$ of patients. $8(16 \%)$ out of 50 patients in the group with nail tip deep to anterior cortex had anterior knee pain while 16 (32\%) out of 50 patients in the group with nail tip protruding from anterior cortex suffered anterior knee pain $(p$-value $=0.061)$.

Conclusion: Intramedullary interlocking nailing in tibial shaft fractures with nail tip deep to anterior cortex showed less pain as compared to nail tip protruding from anterior cortex although it was not statistically significant.
\end{abstract}

Keywords: Anterior knee pain, Intramedullary interlocking nailing, Tibial shaft fractures.

How to Cite This Article: Hassan M, Anwar A, Hassan HU, Saleem MR, Arif U. Comparison of Effects of Different Nail Tip Positions on Anterior Knee Pain After Intramedullary Interlocking Nailing for Tibial Shaft Fractures. Pak Armed Forces Med J 2021; 71(6): 1950-1953.

Doi: https://doi.org/10.51253/pafmj.v6i6.7198

This is an Open Access article distributed under the terms of the Creative Commons Attribution License (https://creativecommons.org/licenses/by-nc/4.0/), which permits unrestricted use, distribution, and reproduction in any medium provided the original work is properly cited.

\section{INTRODUCTION}

Tibial shaft fractures are very commonly encountered by orthopaedic surgeons. One of the recent studies showed that the prevalence of tibial shaft fracture is around $17 / 100000 /$ year. ${ }^{1}$ There have been several methods of managing tibial shaft fractures including non-operative with casting and various operative techniques like Intramedullary Interlocking nails (IM/IL) and various plating techniques. All of these have been compared with each other in different studies and literature has shown that intramedullary nailing can be considered as a better mode of treatment as it shows the lesser risk of complications and better reunion of fracture. $^{2-4} \mathrm{IM} / \mathrm{IL}$ nail delivers satisfactory mechanical stability with commendable fracture alignment and a competent biological environment while preserving soft tissue and blood supply to the bone. It is considered the most common mode of managing tibial shaft

Correspondence: Dr Hassan Udin Hassan, Medical Officer, Department of Orthopaedic, KRL Hospital Islamabad-Pakistan Received: 07 Aug 2021; revision received: 02 Nov 2021; accepted: 04 Nov 2021 fractures by surgeons. ${ }^{3}$

Although IM/IL nail for tibial shaft fracture is a common and popular mode of treatment it also has some disadvantages such as resulting in a common complication of anterior knee pain. In one of the studies, $11 \%$ of the patients treated with intramedullary interlocking nails had clinically significant anterior knee pain after 1 year of follow-up. ${ }^{5}$ Causes of anterior knee pain following intramedullary interlocking nail include skin incision, injury to the intra-articular structures, size of tibial plateau and damage to the infrapatellar branch of the saphenous nerve. ${ }^{6}$ Several studies in the literature have shown that the position of the proximal nail tip may be one of the causative factors of anterior knee pain after tibia nailing. One of the studies showed that anterior knee pain results due to anterior nail prominence of more than $5 \mathrm{~mm}$ and superior prominence of nail closer to the tibial articular surface. ${ }^{7}$ In another study, the tip of the nail position more than $5.5 \mathrm{~mm}$ and $2.5 \mathrm{~mm}$ from tibia plateau and tibial tuberosity respectively were considered factors for anterior 
knee pain. ${ }^{8}$ Another recent study also showed that place of the proximal tip of the tibial nail is a significant factor associated with anterior knee pain, in which $18 \%$ of patients in the group with nail tip deep to the anterior cortex and $37.8 \%$ in the group with nail tip protruding from anterior cortex suffered anterior knee pain. ${ }^{9}$

Although the position of the nail tip has been mentioned in various studies, an important factor as a predictor and etiological factor of anterior knee pain after tibial intramedullary interlocking nailing, very few articles are available regarding nail tip position relative to the anterior cortex of the tibia. This study aimed to compare the frequency of anterior knee pain in intramedullary interlocking nailing after grouping patients according to anterior cortex nail distance (ACN), as it will help the surgeons to determine the better position of nail tip relative to the anterior cortex of the tibia for intramedullary interlocking nailing in the tibia.

\section{METHODOLOGY}

A quasi-experimental study was conducted in the Department of Orthopedic Surgery, Combined Military Hospital Rawalpindi, from October 2018 to April 2019 after the approval from the Institutional Review Board (Ltr no. CPSP/REU/OSG-2016-1201667). A total sample of 100 was calculated by using the WHO sample size calculator, with population size being 2,281,000 and population proportion/prevalence of tibial shaft fractures in Pakistan being $4.16 \%$ as found in a study done in Lahore by Malik et al. ${ }^{10}$ Nonprobability, consecutive sampling technique was used.

Inclusion Criteria: Patients 18-40 years of age of both genders, closed fractures, Gustilo Andersen I (GA I) open tibial diaphyseal fractures and nail tip more than $5 \mathrm{~mm}$ from tibial tuberosity were included in the study.

Exclusion Criteria: Patients who already have other causes of knee pain for example osteoarthritis of knee joint, patients having pathological fractures, patients having renal disease, revision cases, open fracture GAII \& GA-III and patients with knee instability were excluded from the study.

Once the patients were recruited according to the inclusion criteria, the study procedures were explained to the patient and informed consent was attained. We made two groups of the sample size according to anterior cortex nail distance, with the "positive ACN" group indicating patients in which nail tip protrudes from anterior cortex while the "negative $\mathrm{ACN}^{\text {" group }}$ indicates patients in which nail tip is deep to anterior cortex. There was no extra financial burden to the patient except for the cost of the implant which had to be paid by the patient as per hospital policy. The first follow up was 2 weeks after surgery and then every 4 weeks until the union of fracture 16 weeks after surgery. The outcome was measured by pain on the visual analogue scale (VAS) at 16 weeks after surgery.

The data was entered and analyzed using Statistical Package for the social sciences (SPSS) version 22. Quantitative variables like age and BMI were calculated as mean and standard deviation. Qualitative variables like gender and pain were calculated as frequency and percentages. Both groups with positive and negative anterior cortex nail distance (ACN) were compared for pain as per VAS and association of anterior knee pain to age, gender and BMI assessed by applying chi-square test. The $p$-value of $\leq 0.05$ was considered as significant.

\section{RESULTS}

The mean age of the hundred participants was $29.15 \pm 5.29$ years with 18 being the minimum value and 40 being the maximum value. The majority of the patients 51 were between 18-30 years of age. Out of 100 patients, 69 were male and 31 were females. The mean BMI of the study subjects was $28.99 \pm 3.02 \mathrm{~kg} / \mathrm{m}^{2} .30$ patients had BMI $\leq 27 \mathrm{~kg} / \mathrm{m} 2$ and 70 patients had BMI value $>27 \mathrm{~kg} / \mathrm{m} 2$.

In this study, frequency of anterior knee pain after intramedullary interlocking nailing in tibial shaft fractures was found in 24 patients. Eight $(16 \%)$ out of 50 patients in the group with nail tip deep to anterior cortex had anterior knee pain while 16 (32\%) out of 50 patients in the group with nail tip protruding from anterior cortex suffered anterior knee pain. The $p$-value $=0.061$ showed that there was no statistically significant difference between the frequency of anterior knee pain in the two groups as shown in Table-I.

The Association of anterior knee pain in both the ACN distance groups was also evaluated concerning age groups, gender and BMI as shown in Table II. There was not any statistically significant difference found with age groups and BMI of patients. However, while finding an association of anterior knee pain with gender, a statistically significant difference was observed with males having $p$-value $=0.050$. No statistically significant difference was seen with females having $p$ value $=0.552$. Thus, anterior knee pain was not correlated with the age and BMI of the patients but has a relation with the male gender among the patients. 
Table-I: Comparison of the frequency of anterior knee pain after intramedullary interlocking nailing of tibia in the respective two groups.

\begin{tabular}{l|c|c|c}
\hline \multirow{2}{*}{$\begin{array}{l}\text { Anterior Cortex } \\
\text { Nail Distance }\end{array}$} & \multicolumn{2}{|c|}{ Anterior Knee Pain } & \multirow{2}{*}{-value } \\
\cline { 2 - 3 } Yes & No & \\
\hline Positive & $16(32 \%)$ & $34(68 \%)$ & \multirow{2}{*}{0.061} \\
\hline Negative & $8(16 \%)$ & $42(84 \%)$ & \\
\hline
\end{tabular}

Table-II: Association of anterior knee pain with age, gender and body mass index of the patients in both groups.

\begin{tabular}{|c|c|c|c|c|c|}
\hline \multirow{3}{*}{ Factors } & \multicolumn{2}{|c|}{$\begin{array}{c}\text { Positive CAN } \\
(n=50)\end{array}$} & \multicolumn{2}{|c|}{$\begin{array}{c}\begin{array}{c}\text { Negative ACN } \\
(n=50)\end{array} \\
\end{array}$} & \multirow{3}{*}{$\begin{array}{c}p- \\
\text { value }\end{array}$} \\
\hline & \multicolumn{4}{|c|}{ Anterior Knee Pain } & \\
\hline & Yes (\%) & No $(\%)$ & Yes (\%) & No(\%) & \\
\hline \multicolumn{6}{|c|}{ Age (Years) } \\
\hline $18-30$ & $8(16)$ & $17(34)$ & $4(8)$ & $22(44)$ & 0.212 \\
\hline $31-40$ & $8(16)$ & $17(34)$ & $4(8)$ & $20(40)$ & 0.162 \\
\hline \multicolumn{6}{|l|}{ Gender } \\
\hline Male & $9(18)$ & $25(50)$ & $3(6)$ & $32(64)$ & 0.050 \\
\hline Female & $7(14)$ & $9(18)$ & $5(10)$ & $10(20)$ & 0.552 \\
\hline \multicolumn{6}{|c|}{ BMI $\left(\mathrm{kg} / \mathrm{m}^{2}\right)$} \\
\hline$\leq 27$ & $7(14)$ & $22(44)$ & $5(10)$ & $26(52)$ & 0.438 \\
\hline$>27$ & $9(18)$ & $12(24)$ & $3(6)$ & $16(32)$ & 0.062 \\
\hline
\end{tabular}

\section{DISCUSSION}

In the management of tibial shaft fractures, intramedullary nailing is the treatment of choice. ${ }^{11}$ Low percentage of complications like non-union, infection, mal-union, deep venous thrombosis, thermal necrosis and compartment syndrome has been reported following tibial nailing in literature. ${ }^{12}$ The most frequent adverse consequence of tibial nailing is chronic anterior knee pain. A study done by Toivanen has revealed a $69 \%$ incidence of knee pain after tibia nailing after 8 years of follow-up..$^{13}$ Anterior knee pain is multifactorial. Skin incision, injury to intra-articular structures, gender, size of tibial plateau and presence of implant in the medullary cavity are other factors causing anterior knee pain. ${ }^{11}$ Combination of these factors may result in such pain. Therefore, the prediction of developing anterior knee pain after tibial nailing may be difficult based on any single factor. The prominence of nails has been proposed as a major factor causing anterior knee pain by various studies discussed as under. ${ }^{14-16}$

The present study showed $24 \%$ frequency of anterior knee pain with $8(16 \%)$ out of 50 patients in the group with nail tip deep to anterior cortex had anterior knee pain while 16 (32\%) out of 50 patients in the group with nail tip protruding from anterior cortex suffered anterior knee pain. In accordance with our results, a study done by Tahririan in 2014 in Iran, also showed that the position of the proximal tip of the tibial nail is a significant factor associated with anterior knee pain, in which $9(18 \%)$ out of 50 patients in the group with nail tip deep to anterior cortex had anterior knee pain while $17(37.8 \%)$ out of 45 patients in the group with nail tip protruding from anterior cortex suffered anterior knee pain. ${ }^{9}$

Keating et al. revealed an observation that anterior knee pain was more associated with anterior cortex nail distance of more than $5 \mathrm{~mm}$ instead of the height of the nail. Two groups were formulated: one in which insertion of an intramedullary nail was done para-tendinously and another tendon splitting incision group. The results demonstrated the incidence of knee pain to be about $50 \%$ in the first group whereas it was around $80 \%$ in the second group and this was statistically proven with a significant $p$-value of 0.01 . The study recommended a parapatellar tendon incision for insertion of the nail. ${ }^{14}$ However, Bhattacharyya et al. stated that both anterior and superior nail prominence can cause knee pain. This particular study demonstrated that pain at rest is more related to anterior nail prominence whereas pain while kneeling is associated with superior nail prominence. It was also concluded that adequate depth of tip of the nail below the bony cortex will allow for easy removal of nail in the future when required. ${ }^{15}$

A local study done by Ahmed in Lahore concluded in his study that anterior knee pain is linked with injury of the infrapatellar branch of the saphenous nerve. ${ }^{16}$ Obremskey et al, found out that in their study smoking, comminuted fractures, and surgeons with less than 5 years of experience were some predictors of knee pain. ${ }^{17,18}$

Darabos et al studied patients, who had undergone intramedullary nails and evaluated the distance from the tip of the nail to the tibial plateau and tibia tuberosity on lateral knee radiographs. It was concluded that the position of the tip of the nail and its adverse impact on the innervation pattern of the area dorsal to the patellar tendon could lead to anterior knee pain. ${ }^{19}$ In contrast to our study; Cartwright-Terry et al, had shown that $83 \%$ of patients developed anterior knee pain after tibial nailing. Their study revealed that those who were manual workers developed more knee pain after tibial nailing. ${ }^{20}$ Hence, it is in order to speculate that information about the occupation and lifestyle of the participants is important. The results of another study were somewhat close to our results as they showed that about $10 \%$ of the patients under- 
going intramedullary interlocking nails had clinically significant anterior knee pain. ${ }^{5}$

In contrast to Cartwright-Terry et al, study and the present study that found no relationship between age and knee pain, Court-Brown et al, have reported that patients with knee pain after tibial nailing were significantly younger. ${ }^{21}$ Our study found an association between male gender and anterior knee pain. However, Kim et al, have reported that knee pain after tibial nailing was more common among women. In accordance with our results, Kim et al. also found no relationship between age and type of fracture and knee pain.22 Bakhsh et al, compared the semi-extended lateral parapatellar, medial parapatellar, and tendon splitting groups regarding knee pain severity, location and functional outcome. The study revealed that there is no significant difference among these three approaches of intramedullary nailing resulting in knee pain. ${ }^{23}$ Another ultrasonographic study evaluated 32 patients who underwent intramedullary nailing revealed that the patellar tendon in the painless group was wider and thicker while that of 10 patients with knee pain there was not any different. Therefore, the thicker and wider tendon is less related to knee pain. ${ }^{24}$

Very scarce literature has been observed regarding the nail tip positioning during IM/IL, which can result in lesser anterior knee pain. This study bridges this gap in literature contributing to the knowledge about the nail tip positioning for tibial shaft fractures resulting in less pain and morbidity. Thus, our study recommends that the nail tip deep to anterior cortex technique should be used as a first-line technique in intramedullary interlocking nailing in tibial shaft fractures to reduce the morbidity of these patients.

\section{LIMITATION OF STUDY}

As it was a single-centre study with a small sample size in a limited time period, further longitudinal studies are recommended in the Pakistani population.

\section{CONCLUSION}

Intramedullary interlocking nailing in tibial shaft fractures with nail tip deep to anterior cortex showed less pain as compared to nail tip protruding from anterior cortex although it was not statistically significant.

\section{Conflict of Interest: None.}

\section{Authors' Contribution}

$\mathrm{MH}$ : Contributed to the concept, design and data collection, $\mathrm{HUDH}$ : Contributed to the data analysis and write up, AA: Contributed to the write-up and proof reading of the manuscript, MRS: Contributed to the design and critical review of the manuscript, UA: Contributed to the design and literature review.

\section{REFERENCES}

1. Larsen P, Elsoe R, Hansen SH, Graven-Nielsen T, Laessoe U. Incidence and epidemiology of tibial shaft fractures. Injury 2015; 46(4): 746-750.

2. Obremskey WT, Cutrera N, Kidd CM. A prospective multi-centre study of intramedullary nailing vs casting of stable tibial shaft fractures. J Orthop Traumatol 2017; 18(1): 69-76.

3. Mukherjee S, Arambam MS, Waikhom S, Santosha, Masatwar PV, Maske RG. Interlocking Nailing Versus Plating in Tibial Shaft Fractures in Adults: A Comparative Study. J Clin Diagn Res 2017; 11(4): RC08- RC13.

4. Wang B, Zhao Y, Wang Q, Hu B, Sun L, Ren C, et al. Minimally invasive percutaneous plate osteosynthesis versus intramedullary nail fixation for distal tibial fractures: a systematic review and metaanalysis. J Orthop Surg Res 2019; 14(1): 1-9.

5. Obremskey W, Agel J, Archer K, To P, Tornetta P. SPRINT Investigators. Character, incidence, and predictors of knee pain and activity after infrapatellar intramedullary nailing of an isolated tibia fracture. J Orthop Trauma 2016; 30(3): 135-141.

6. Bishop JA, Campbell ST, Eno JJ, Gardner MJ. Knee pain after intramedullary nailing of tibia fractures: prevalence, aetiology, and treatment. J Am Acad Orthop Surg 2018; 26(18): 381-387.

7. Soraganvi PC, Anand-Kumar BS, Rajagopalakrishnan R, Praveen-Kumar BA. Anterior knee pain after tibial intramedullary nailing: is it predictable? Malays Orthop J 2016; 10(2): 16-20.

8. Jia P, Lu FC, Ullah K, Zhang M. Angle stable interlocking intramedullary nails for tibial plateau fractures. Orthop Surg 2018; 10(2): 115-120.

9. Tahririan MA, Ziaei E, Osanloo R. Significance of the position of the proximal tip of the tibial nail: an important factor related to anterior knee pain. Adv Biomed Res 2014; 3(1): 119-123.

10. Malik Al, Iqbal M, Mehboob I. Incidence of Adult Open Tibial Shaft Fractures. 6-Years Study in Lahore General Hospital Lahore, Pakistan. Pak Postgrad Med J 2016; 27(3): 79-81.

11. Serbest S, Tiftikçi U, Çoban M, Çirpar M, Daglar B. Knee pain and functional scores after intramedullary nailing of tibial shaft fractures using a suprapatellar approach. J Orthop Trauma 2019; 33(1): 37-41.

12. Clark D, Vo LU, Piscoya AS, Chan A, Dunn JC. Systematic review and analysis of the quality of randomized controlled trials comparing reamed and unreamed intramedullary nailing of tibial fractures. J Orthop Trauma 2021; 35(2): 59-64.

13. Toivanen JA, Väistö $\mathrm{O}$, Kannus $\mathrm{P}$, Latvala K, Honkonen SE, Järvinen MJ Anterior knee pain after intramedullary nailing of fractures of the tibial shaft: a prospective, randomized study comparing two different nailinsertion techniques. J Bone Joint Surg 2002; 84-A(4): 580-585.

14. Keating JF, Orfaly R, O'Brien PJ. Knee pain after tibial nailing. J Orthop Trauma 1997; 11(1): 10-13.

15. Bhattacharyya T, Seng K, Nassif NA. Knee pain after tibial nailing. The role of nail prominence. Clin Orthop Relat Res 2006; 449(1): 303-307.

16. Ahmad S, Ahmed A, Khan L, Javed S, Ahmed N, Aziz A. Comparative analysis of anterior knee pain in transpatellar and medial parapatellar tendon approaches in tibial interlocking nailing. J Ayub Med Col Abbot 2016; 28(4): 694-697.

17. Obremskey W, Agel J, Archer K, To P, Tornetta P. Character, incidence, and predictors of knee pain and activity after infra-patellar intramedullary nailing of an isolated tibia fracture. J Orthop Trauma. 2016; 30(3): 135-141.

18. Lee C, Zoller SD. Pearls and pitfalls with intramedullary nailing of proximal tibia fractures. J Am Acad Orthop Surg 2020; 28(2): 66-73.

19. Darabos N, Banic T, Lubina Z, Daraboš A, Bilić V, Sabalić S. Precise nail tip positioning after tibial intramedullary nailing prevents anterior knee pain. Int Orthop 2013; 37(8): 1527-1531.

20. Cartwright-Terry $M$, Snow $M$. The severity and prediction of anterior knee pain post tibial nail insertion. J Orthop Trauma 2007; 21(6): 381-385.

21. Court-Brown CM. Knee pain after intramedullary tibial nailing: Its incidence, aetiology, and outcome. J Orthop Trauma 1997; 11(2): 103-105.

22. Kim KT, Sohn SK, Kang MS, Jin X, Lee CH. Anterior knee pain after intramedullary tibial nailing. J Korean Orthop Assoc 2009; 44(1): 61-67.

23. Bakhsh WR, Cherney SM, McAndrew CM, Ricci WM, Gardner MJ. Surgical approaches to intramedullary nailing of the tibia: a comparative analysis of knee pain and functional outcomes. Injury 2016; 47(4): 958-961.

24. Erinç S, Esenkaya I, Poyanlı OŞ, Özturan B, Ayaz M, Öztürk AT. Ultrasonographic comparison of bilateral patellar tendon dimensions in patients treated via intramedullary tibial nailing using a transpatellar approach. Acta orthop Traumatol Turc 2018; 52(6): 423-427. 